\title{
Developing a Motor Skill-Based Curriculum for Preschools and Kindergartens as a Preventive Plan for Children With Obesity in Indonesia
}

\author{
S Bakhtiar*, R Famelia, R Syahputra, I Oktavianus, and J Goodway ${ }^{2}$ \\ ${ }^{1}$ Faculty of Sports Sciences, Universitas Negeri Padang, Prof. Dr. Hamka, Padang, Indonesia \\ ${ }^{2}$ Kinesiology: Physical Education, Department of Human Sciences, School of Education and Human Ecology, The Ohio \\ State University, 305 Annie \& John Glenn Ave, 43210, Columbus, Ohio, USA \\ *Corresponding author. Email: syal_fik@yahoo.com
}

\begin{abstract}
Indonesia has faced up malnutrition and non-communicable issues for years, yet currently Indonesia turned out to be ranked at the top ten most obese countries in the world. The trajectory of the rate of obesity is increasing from childhood to adolescence. Physical inactivity is a factor that contributes to this obesity crisis. Therefore, a preventive action should be comprehensively planned in Indonesia, started from the early age. Fundamental motor skills (FMS) have shown a contribution to the likelihood to be physically active. Therefore, the purpose of this study is to develop a structured physical activity program to promote motor skill competence for early childhood to be implemented at preschools and kindergarten. This study reports a preliminary data of preschoolers/kindergarteners competence on FMS and a design of motor skill program that has been piloted in Padang, West Sumatera. The initial analysis of over 100 young children in Indonesia showed that they had low motor skills competence. Therefore, a motor skill program has been designed and piloted. If the results showed the effectiveness of this program to promote children competence on motor skills, it will be implemented in statewide in West Sumatera.
\end{abstract}

\section{Keywords: Curriculum, Locomotor, Object Control, Preschools, Children, Obesity}

\section{INTRODUCTION}

Obesity has been a global concern as the obesity rates in many countries across the world have increased, and nearly doubled since 1980 [1]. This concern is getting worst because approximately 43 million children across the globe under the age of five were overweight in 2010, and they are on a trajectory for obesity and hypokinetic disease [1]. On top of this, physical inactivity is now identified as the fourth leading risk factor for global mortality[2]. As a result, the global agenda has turned to the importance of promoting physical activity as an attempt to reduce obesity and chronic disease. Indonesia is also facing this obesity issue as Indonesia has just joined the ranks of the top 10 most obese countries in the world [3]. The obesity in Indonesia is a part of double burden problem, in which underweight and overweight problems are coexisting [4]. For years, Indonesia has faced noncommunicable disease and malnutrition issue due to poverty, which led to stunted growth on children [4], [5]. Then, the increasing in economic sectors and urbanization in Indonesia has led to an easier access for Indonesian children to get adequate energy intake. Unfortunately, this would increase the possibility of stunted children to be obese when they receive more nutrition [5], [6]. Besides the changes in food intake, the increase in sedentary behavior also contributes to the increasing of obesity rate in Indonesian children. In many cases, time spent in physical activity has been replaced by screen activities [7]. On average, Indonesian children spent about 5.5 hours watching television and spent 3.4 hours on playing electronic game and internet per day on school days and around 7.4 hours on watching television and 5.9 hours on playing electronic game and internet on holiday [8]. This data has raised awareness of Indonesian scholars that Indonesia must respond quickly and highlight the importance of diet and physical activity programs starting in the early childhood years [9], [10], [11].

Given these points, Indonesia needs to start creating a strategic population based plan to prevent the increasing obesity rate to achieve a wide-scale impact. School could be a place to start implementing a population based approach program. Since preschools enrolment rates have been increasing in Indonesia[12], it can provide an appropriate access for a preventive action plan. However, in Indonesia, there has been a shift from a play-based curriculum to a heavy focus on academic content, such as reading, writing and arithmetic. This curriculum has been criticized as not being appropriate for younger children [13]. This situation could be worse because there are no national physical activity guidelines for preschools. Moreover, Indonesia has lack of data concerning appropriate physical activity programs for preschoolers to 
develop these national guidelines. Thus, there is a critical need for evidence-based physical activity data that can be used to develop the physical activity program guideline for preschools.

As physical activity has been recognized as an important factor to prevent the increasing of the obesity rate, some countries have developed physical activity guidelines. For instance, the USA and UK recommend 60 minutes of moderate-to-vigorous physical activity (MVPA) per day to maintain a healthy cardiorespiratory and metabolic risk profile [2]. The World Health Organization (WHO) also recommends that children and youth aged 5-17 years should accumulate at least 60 minutes of MVPA daily to stay healthy [2]. However, Indonesia does not currently have such guidelines. Yet, the World Health Organization (WHO) also recommends that all private and public sectors "have vital roles to play in creating healthy environments and contributing to the promotion of physical activity" [2] and that member states need to "identify potential solutions" and "develop strategies" that promisingly make a wide-scale impact [14].

In order to be able to develop an appropriate physical activity program for preschoolers, we need to understand what factors influencing children to be physically active. A conceptual model proposed by US scholars, Stodden and colleagues, suggests that motor competence is interrelationship with physical activity [15]. This relationship is mediated by perceived motor competence and physical fitness, and it becomes stronger along with the age from early childhood to later childhood [15]. This model has been supported by empirical evidences [15], [16], [17]. Therefore, this model emphasizes that it is important to develop children motor skill competence at young age in order to support them to be physically active so forth. What has been found in Indonesia also suggest that this model is also faced in Indonesia context. A study conducted by Sularyo and Akhib in Lombok, Indonesia, demonstrated that most children experienced growth delay in terms of gross-motor skills as well as their social, language and fine motor development, with these delays increasing across age [13]. Along with this data, some studies undertaken at elementary school students in West Sumatera found that students' low motor competence were not developed normally [18]. Such data may contribute to the increasing sedentary lifestyles among adolescence that leads to an increase in overweight and obesity rate. However, up to now, there is no data about preschoolers motor skills development which informs the existence of physical activity program. Thus, it calls for attention to collect motor skill competence data [19] of Indonesian preschooler to guide us in designing an evidence-based physical activity program to be implemented at preschool. Therefore, the primary purpose of this study was to evaluate preschoolers' motor skill competence as the guidance for the authors to develop a structured physical activity program in promoting children motor skill competence. Another purpose of this study was to introduce the preliminary design of physical activity program for preschoolers to promote their motor skill competence. We hypothesized that Indonesian preschoolers have low motor skill competence and therefore an appropriate program to improve their motor skill competence is needed. This study is a part of a threeyear plan project started at 2017 up to 2019. This article reported preliminary data obtained from initial phase conducted on the first year. Thus, the results reported in this study were analyzed from an on going research as a prior data to design such program.

\section{RESEARCH METHOD}

2.1 Research procedures and participant

This study was conducted in Padang, West Sumatera, Indonesia. One hundred and two of preschoolers (aged 4-6 years, $M_{\text {age }}=60.72$ mo., $S D=7.59$ ) participated in this study. Fifty-three pre-schoolers (26 boys, 27 girls) were recruited from three preschools in urban area and forty-nine pre-schoolers (26 boys, 23 girls) were recruited from three preschools in rural area. None of the participants were identified having any forms of disabilities.

\subsection{Instruments}

This study investigated the motor skill competence of Indonesian pre-schoolers. The Test of Gross Motor Development $3^{\text {rd }}$ edition (TGMD-3) was used to collect participants motor skill competence[20]. TGMD-3 is a criterion-referenced assessment of FMS for children ages 3-10 years that consists of 2 subscales, locomotor and ball skills. The locomotor subscale measures running, skipping, hopping, sliding, galloping, and horizontaljumping skills with the range of total score is 0 to 46 points. The ball skills subscale assesses two-hand striking, one-hand striking, catching, dribbling, overhand throwing, kicking, and underhand throwing with the range of total score is 0 to 54 points.

\subsection{Data Analysis}

All statistical analysis were conducted in IBM SPPS Statistics 23 package and statistical significance was set as $p<.05$. Descriptive statistics (means and standard deviation) were conducted. These data were analyzed for Analysis of Variance (ANOVA) assumption. This analysis was used to calculate separated data of locomotor and ball skills taken from different gender (two separate 2 gender (girl, boy) X 2 location (urban, rural). Then, the result of these analyses was used to design a structured physical activity program.

\section{RESULTS AND DISCUSSION}

3.1. Description of preschooler motor skill competence.

The descriptive analysis of TGMD-3 scores on both locomotor and ball skills showed that overall participants score was less than half of the total score. This finding indicated that on average, Indonesian children have low competence in both locomotor and object control skills. Table 1 below shows the detail of description analysis for both locomotor and ball skills. 


\begin{tabular}{|c|c|c|c|c|c|c|c|c|c|}
\hline & \multirow{2}{*}{\multicolumn{3}{|c|}{ Urban $(\mathrm{N}=53)$}} & tence o & schor & & & & \\
\hline \multirow[b]{2}{*}{ Variables } & & & & \multicolumn{3}{|c|}{ Rural $(\mathrm{N}=49)$} & \multicolumn{3}{|c|}{ Total } \\
\hline & $\begin{array}{c}\text { Boys } \\
\text { Mean (SD) }\end{array}$ & $\begin{array}{c}\text { Girls } \\
\text { Mean (SD) }\end{array}$ & $\begin{array}{c}\text { Total } \\
\text { Mean (SD) }\end{array}$ & $\begin{array}{l}\text { Boys } \\
\text { Mean } \\
\text { (SD) }\end{array}$ & $\begin{array}{c}\text { Girls } \\
\text { Mean } \\
\text { (SD) }\end{array}$ & $\begin{array}{c}\text { Total } \\
\text { Mean } \\
\text { (SD) }\end{array}$ & $\begin{array}{l}\text { Boys } \\
\text { Mean } \\
\text { (SD) }\end{array}$ & $\begin{array}{c}\text { Girls } \\
\text { Mean } \\
\text { (SD) }\end{array}$ & $\begin{array}{l}\text { Total } \\
\text { Mean } \\
\text { (SD) }\end{array}$ \\
\hline $\begin{array}{l}\text { Locomotor skills } \\
\qquad(0-46)\end{array}$ & $\begin{array}{l}18.38 \\
(6.13)\end{array}$ & $\begin{array}{l}19.85 \\
(5.74)\end{array}$ & $\begin{array}{l}19.13 \\
(5.92)\end{array}$ & $\begin{array}{l}16.69 \\
(4.78)\end{array}$ & $\begin{array}{l}18.30 \\
(5.46)\end{array}$ & $\begin{array}{l}17.45 \\
(5.12)\end{array}$ & $\begin{array}{l}17.54 \\
(5.51)\end{array}$ & $\begin{array}{l}19.14 \\
(5.60)\end{array}$ & $\begin{array}{l}18.32 \\
(5.59)\end{array}$ \\
\hline $\begin{array}{l}\text { Ball skills } \\
\quad(0-54)\end{array}$ & $\begin{array}{l}17.31 \\
(3.71)\end{array}$ & $\begin{array}{l}15.96 \\
(3.11)\end{array}$ & $\begin{array}{l}16.62 \\
(3.45)\end{array}$ & $\begin{array}{l}17.96 \\
(5.16)\end{array}$ & $\begin{array}{l}14.43 \\
(4.24)\end{array}$ & $\begin{array}{l}16.31 \\
(5.03)\end{array}$ & $\begin{array}{l}17.63 \\
(4.46)\end{array}$ & $\begin{array}{l}15.26 \\
(3.71)\end{array}$ & $\begin{array}{l}16.47 \\
(4.26)\end{array}$ \\
\hline
\end{tabular}

In comparison to other studies, Indonesian preschoolers have lower competence on both locomotor and object control skills compared to Brazilian preschoolers [21]. Brazilian boys had 28.8 scores and girls had 27.8 scores on the locomotor skills, and boys had 31.1 scores and girls had 24 scores in object control skills. Unlikely, Indonesian children performed less competent on locomotor skills and object control skills than western children [22], [23]. Clearly, the finding signals that compare to other developing and developed countries, Indonesian preschoolers have lower competence on their motor skill.

\subsection{Gender and location differences on motor competence skills}

A two way (2 Gender x 2 Location) ANOVA analysis on locomotor skill analysis showed that there was no main effects of Gender ( $p=17)$ and no main effects of school location difference $(p=.14)$ on locomotor skills. Furthermore, another two way (2 Gender x 2 Location) ANOVA analysis was conducted on ball skill scores. It was found that there was main effect of Gender $\left(F_{[1,98]}=8.91, \quad p=.004\right)$ on ball skills, in which boys $(M=17.85)$ performed better than girls $(M=15.91)$, but there was no main effects of Location $(p=.47)$ on ball skills. Yet, there was no main effects of Location $(p=.59)$ on ball skills. Further analysis showed that there were no significant Gender X Location interactions for any analyses.

The findings showed similar global trends relative to motor skill competence and gender differences [24], [17], [25], [21], in which Indonesian preschool boys performed better than girls in ball skills. Cultural differences might contribute to these findings, in which young boys in Indonesia are more likely to play outside after school than girls. This is true also for boys in urban and rural areas. That is why we did not find location differences on both children's locomotor and object control skills. Another possible explanation about this gender differences on object control skills is the society values on sports, which is more associated with boys then girls. Therefore, boys may have higher motivation to participate in ball skills than girls.
3.3. Designing a structured physical activity program to promote motor skill competence to Indonesian preschoolers

In USA, an evidenced-based motor skill program called SKIP (Successful Kinesthetic Instruction for Preschoolers) has been developed by Goodway and colleagues. Some researchers have been reporting evidences showing significant effects of SKIP program in improving motor competence and perceptions of motor competence [25], [26], [27], [28]. This program includes intervention for children's motor competence, and has been delivered with a dose of 30-45 mins, two times per week for 9 to 12 weeks. Since motor skill competence of Indonesian children is considered stunted, SKIP program could be used as a guide to design an appropriate physical activity program for children motor skill development. However, some modifications are needed to suit Indonesian culture and preschool situation. Therefore, this structured physical activity program is called as INDOSKIP program.

The INDO-SKIP program is designed based on Dynamic Systems Theory [29], [30]. The Dynamic Systems Theory captures that the development change is dynamic. It means that the change is not linear [29], [30], which allows individual to experience different pathways to produce the same results. This point is very important because every child is unique. Each individual has different pathways to grow and develop [31]. This concept is essential in designing motor skill intervention, because one approach does not fit for all. Different children may need different approach to get the same result to promote their motor development. Newell's Constraints perspective [30] is part of dynamic systems theory and suggests that motor skills do not naturally emerge, but rather are the result of the interactions of subsystems between the learner, environment and task. Manipulation of task and environmental constraints, including factors such as ball size, distance thrown etc. will occur to design the developmentally appropriate and motivating tasks for the INDO-SKIP intervention.

The INDO-SKIP program is designed based on five task principles, they are: 1) The lessons should be developmentally appropriate based upon the stage of children at their motor development sequences [32], [16]. 
Therefore, the lessons are not based on the age of the children but their competence on the skill. It is common that two children in the same age and gender will show different competence on motor skills. 2) The lessons are task based analysis designed. Therefore, some activities can be designed from simpler to more complex through extension, refinement, and application [33]. For instance, in catching activities, the tasks are designed by modifying the size and the weight of the ball, from the easier to the more difficult to catch [25], [26], [27], [28]. 3) The task are individualized, but are still accommodated by a teacher when she/he teaches the lessons in class. 4) The learning experience is developed to provide maximum opportunity for children to practice each skill. Therefore, equipment is provided for each child to do the tasks [25], [26]. 5) Repetitive cycles of skills. This means that the skills and tasks will be taught as an overall block plan. The first cycle would be more toward introducing skills to children through simpler tasks, the next cycles would be practicing the more advance tasks for each fundamental motor skill.

As each skill in locomotor skills and object control skills has three to five developmental stages [16] the time proportion for each skill will be vary. For instance, catching a ball has five developmental stages. Therefore, tasks related to catching skills will be taught more often than gallop, which has three developmental stages. Since this study reported the initial steps of three-year research plan, and the INDO-SKIP has just been designed and prepiloted, the initial data of the INDO-SKIP feasibility and efficacy data has not enabled to be reported in this study yet.

\section{CONCLUSION}

Overall, this study has provided preliminary data to inform the authors in designing an appropriate physical activity program to promote preschoolers' motor competence. It was found that Indonesian preschoolers had poor competence in their locomotor skills and object control skill. These findings highlighted the need for Indonesia to design a program for preschoolers to support their motor development. Therefore, the INDO-SKIP program has been designed by authors. As this study was a part of a larger study, the next step of this study is piloting the INDO-SKIP curriculum to examine the feasibility of INDO-SKIP program to promote children's motor competence. Furthermore, future research would also investigate factors associated with children's motor skill development, as other benefits of INDO-SKIP program.

\section{ACKNOWLEDGMENTS}

This research was supported by The Ministry of Research, Technology and Higher Education of Republic of Indonesia and The Ohio State University. The authors would like to thank the directors, teachers, children, and parents from the preschool centres for their support throughout this study. In addition, the authors thank the assistance of undergraduate students, graduate students and faculty member at Universitas Negeri Padang. This study was conducted as part of a partnership with The
Ohio State University supervised by Dr. Jacqueline Goodway.

\section{REFERENCES}

[1] World Health Organization. Obesity and overweight factsheet. Retrieved from: http://www.who.int/mediacentre/factsheets/fs311/ en/. Oct $25^{\text {th }}, 2014$, pp 45-54.

[2] World Health Organization. Global recommendations on physical activity for health. Retrieved from: http://www.who.int/dietphysicalactivity/leafletphysical-activity-recommendations.pdf . March 17, 2012, pp. 23-55.

[3] Organization for Economic Co-operation and Development Obesity Update. Publication of OECD Directorate for Employment, Labor and Social Affairs. 2014, pp 45-49.

[4] Hanandita, W., \& Tampubolon, G. "The double burden of malnutrition in Indonesia: Social determinants and geographical variations". SSMPopulation Health, 1, 2015, pp. 16-25.

[5] Julia, M., Van Weissenbruch, M. M., Delemarrevan de Waal, H. A., \& Surjono, A. "Influence of socioeconomic status on the prevalence of stunted growth and obesity in prepubertal Indonesian children". Food and nutrition bulletin, 25 April 2004, pp354-360.

[6] Popkin, B. M., Richards, M. K., \& Montiero, C. A. "Stunting is associated with overweight in children of four nations that are undergoing the nutrition transition". The Journal of nutrition, 126 Dec 1996, pp 3009.

[7] Collins, A. E., Pakiz, B., \& Rock, C. L. "Factors associated with obesity in Indonesian adolescents". International Journal of Pediatric Obesity: Ijpo: an Official Journal of the International Association for the Study of Obesity, 3, January 01, 2008, pp. 58-64.

[8] Hendriyani, Hollander, E., d'Haenens, L., \& Beentjes, J. W. "Children's media use in Indonesia". Asian Journal of Communication, 22 March 2012, pp 304-319.

[9] Roemling, C., \& Qaim, M. "Obesity trends and determinants in Indonesia". Appetite, 58, March 2012, pp 13-34.

[10] Goodway, J. D., Famelia, R., \& Bakhtiar, S. "Future directions in physical education \& sport: developing fundamental motor competence in the early years is paramount to lifelong physical activity" Asian Social Science, 10 May 2014, pp. 44-52.

[11] Famelia, R., Goodway, J., \& Bakhtiar, S. "Exploring the physical activity, actual motor competence, and perceived motor competence of urban and rural Indonesian preschoolers". Journal 
of Sport \& Exercise Psychology, (supplement) S63-S64. 2017, pp. 56-66.

[12] Bappenas. Early Childhood Development Strategy Study in Indonesia. Jakarta: The ministry of national development planning/national development planning agency (Bappenas). 2013, pp 52.

[13] United Nations Educational, Scientific and Cultural Organization (UNESCO). National Case Study on the Situation of Early Childhood Care and Education Services in Indonesia. Background Information for the Fifth Ministerial Review Meeting of the Nine High-Population Countries on Education for All. Jakarta, Indonesia: UNESCO Office. 2003, pp 45-66.

[14] World Health Organization Prioritizing areas for action in the field of population-based prevention of Childhood obesity. Retrieved from: http://www.who.int/dietphysicalactivity/childhood /tools/en/ . March 15 ${ }^{\text {th }}, 2012$ pp 12

[15] Stodden, D. F., Goodway, J. D., Lagendorfer, S. A, Roberton, M. A., Rudisill, M.E., Garcia, C., \& Garcia, L. "A developmental perspective on the role of physical competence in physical activity: An emergent relationship". Quest,60, 2008, pp. 290-306.

[16] Gallahue, D. L., Ozmun, J. C., \& Goodway, J. D. "Understanding motor development: Infants, children, adolescents, adults ( $7^{\text {th }}$ ed.)". New York, NY: McGraw Hill. 2012, pp. 25-45.

[17] Robinson, L. E., Stodden, D. F., Barnett, L. M., Lopes, V. P., Logan, S. W., Rodrigues, L. P., \& D'Hondt, E. "Motor competence and its effect on positive developmental trajectories of health”. Sports Medicine, 45 Sept 2015, pp. 12731284.

[18] Famelia, R., Goodway, J., Bakhtiar, S., \& Mardela, R. "Investigating the Motor Competence and Physical Activity of Indonesian, Muslim Preschoolers from Urban and Rural Areas"\% Journal of Sport \& Exercise Psychology, (supplement) S33. 2016, pp. 63-66.

[19] Bakhtiar, S., Famelia, R., Goodway, J.D., \& Kiram, Y. A "Needs Assessment of the Fundamental Motor Skills of Urban and Rural Children in Indonesia". Journal of Sport and Exercise Psychology, 37, (supplement) S72. 2015, pp. 23-44.

[20] Ulrich, D. A. "The Test of Gross Motor Development, 3rd edition" Retrieved from: https://sites.google.com/a/umich.edu/tgmd3/home. May 30th. 2016, pp. 45-55.

[21] Valentini, N. C., Logan, S. W., Spessato, B. C., de Souza, M. S., Pereira, K. G., \& Rudisill, M. E. "Fundamental Motor Skills Across Childhood: Age, Sex, and Competence Outcomes of Brazilian
Children". Journal of Motor Learning and Development, 4 Jan 2016, pp. 16-36.

[22] Estevan, I., Molina-García, J., Queralt, A., Álvarez, O., Castillo, I., \& Barnett, L. "Validity and Reliability of the Spanish Version of the Test of Gross Motor Development-3". Journal Of Motor Learning \& Development, 5 Jan 2017, pp. 69-81.

[23] Wagner, M. O., Webster, E. K., \& Ulrich, D. A. "Psychometric Properties of the Test of Gross Motor Development, Third Edition (German Translation): Results of a Pilot Study". Journal Of Motor Learning \& Development, 5 Jan 2017, pp 29-44.

[24] Goodway, J.D., Robinson, L., \& Crowe, H. "Gender differences in fundamental motor skill development in disadvantaged preschoolers in two geographical regions". Research Quarterly for Exercise \& Sport, 81.Jan 2010,pp. 17-24.

[25] Goodway, J., \& Branta, C. "Influence of a motor skill intervention on fundamental motor skill development of disadvantaged preschool children". Research Quarterly for Exercise and Sport, 74. Jan 2003, pp. 36-46.

[26] Humeric, I. "The effects of two motor skill interventions on preschool children's object control skills and their perceived motor competence". (Unpublished doctoral dissertation). The Ohio State University, Columbus, OH. 2010, pp. 89-97.

[27] Robinson, L. E., \& Goodway, J. D. "Instructional climates in preschool children who are at-risk. Part I: Object control skill development". Research Quarterly for Exercise and Sport, 80, 2009, pp. 533-542

[28] Goodway, J. D., Brian, A., Chang, S. H., Famelia, R., Suda, E., \& Robinson, L. E. "Promoting physical literacy in the early years through Project SKIP”. ICSSPE Bulletin-Journal of Sport Science and Physical Education, 65, Jan 2013, pp. 121129.

[29] Thelin, E. "Motor development: A new synthesis". American Psychologist, 50, 1995, pp. 79-95.

[30] Newell, K. M. "Constraints on the development of coordination". In M. G. Wade \& H. T. A. Whiting (Eds.), Motor development in children: Aspects of coordination and control .1986, pp. 341-360). Dordrecht, The Netherlands: Nijhoff.

[31] Bakhtiar, S. "The implementation of dynamic system theory and the principles of growth in physical education of elementary school". Asian Social Science, 9 Dec 2013, pp 105-121.

[32] Bakhtiar, S. "Fundamental motor skill among 6year-old children in Padang, West Sumatera, Indonesia". Asian Social Science, 10 May 2014, pp 155-158.

[33] Rink, J. . "Teaching physical education for learning”. NY: McGraw-Hill. 2009, pp 65-68. 